\title{
Glutathione S-Transferases in Small Intestinal Mucosa of Patients with Coeliac Disease
}

\author{
Peter J. Wahab, ${ }^{1}$ Wilbert H. M. Peters, ${ }^{2}$ Hennie M. J. Roelofs ${ }^{2}$ and Jan B. M. J. Jansen ${ }^{2}$ \\ ${ }^{1}$ Department of Gastroenterology and Hepatology, Rijnstate Hospital Arnhem, PO Box 9555, 6800 TA, \\ Arnhem, The Netherlands and ${ }^{2}$ University Hospital Nijmegen, PO Box 9101, 6500 HB, Nijmegen, \\ The Netherlands
}

Patients with villous atrophy due to coeliac disease have an increased risk of developing small intestinal malignancies. Intestinal glutathione (GSH) and glutathione S-transferases (GST) are involved in the protection against carcinogenesis. The aim of this study was to evaluate GSH content and GST enzyme activity in small intestinal mucosa of untreated coeliacs compared to controls. We evaluated GSH content and GST enzyme activity, including the levels of GST classes $\alpha, \mu, \pi$ and $\theta$, in small intestinal biopsies of untreated coeliacs (flat mucosa, Marsh IIIC, $n=12$ ) compared to normal subjects $(n=23)$. Next, we evaluated GSH and GST's in coeliacs in remission (Marsh 0-I, $n=11$ ), coeliacs with persisting villous atrophy while on a gluten-free diet (partial villous atrophy, Marsh IIIA $(n=5)$; subtotal villous atrophy, Marsh IIIB $(n=6)$ ) and patients with infiltrative/crypt-hyperplastic Marsh II lesions $(n=4)$. Total GST enzyme activity and content of GST $\alpha$ are markedly suppressed in Marsh IIIC lesions compared to controls (resp. $220 \pm 79$ vs. $464 \pm 189 \mathrm{nmol} / \mathrm{mg}$ protein $\cdot \min (P<0.001)$ and $2.79 \pm 2.46 \mathrm{vs} .6 .47 \pm 2.29 \mu \mathrm{g} / \mathrm{mg}$ protein $(P<0.001))$. In coeliacs in remission these levels normalized. Total GST enzyme activity and GST $\alpha$ levels are proportionately lowered according to the degree of mucosal pathology in Marsh II, IIIA and IIIB. (Spearman's $\sigma$ correlation coefficient for total GST, $-0.596, P<0.001 ;$ GST $\alpha,-0.620, P<0.001$ ). GST $\mu, \pi$ and $\theta$ and GSH levels are not significantly different in the selected study groups of mucosal pathology compared to controls. Total GST enzyme activity and content of GST $\alpha$ in small intestinal mucosa are significantly lower in untreated coeliac disease compared to controls. In Marsh II, IIIA and IIIB, GST enzyme activity and GST $\alpha$ content are proportionally lower according to the degree of mucosal pathology. Normal values are seen in coeliacs in remission. This correlation between coeliac disease and a suppressed GSH/GST detoxification system may explain in part the carcinogenic risk in untreated coeliac disease.

Key words: Coeliac disease - Glutathione - Glutathione S-transferase — Small intestine

Patients with untreated coeliac disease, i.e. gluten-sensitive enteropathy with villous atrophy of the small intestinal mucosa, have an increased risk of developing small intestinal malignancies, especially lymphomas and carcinomas. ${ }^{1-6)}$ Tumor risk figures return to those of the general population after successful response to a gluten-free $\operatorname{diet}^{3,7)}$ The pathophysiologic mechanism responsible for the increased tumour incidence in active coeliac sprue is unknown, but may be related to a decreased capacity of the small intestinal mucosa to handle (detoxify) toxic or carcinogenic substances. Detoxification enzymes, like glutathione S-transferases (GST) are presumed to play an important role in the protection against toxic, carcinogenic substances. They are present in most epithelial tissues of the human gastrointestinal tract. ${ }^{8-14)}$ Increasing evidence is reported of a close correlation between increased cancer incidence and decreased activity of GST. ${ }^{9,15)}$

\footnotetext{
${ }^{1}$ To whom correspondence should be addressed.

E-mail: pwahab@rijnstate.nl
}

Human cytosolic GST are a family of dimeric enzymes of which the main classes $\alpha, \mu, \pi$ and $\theta$ are recognized. ${ }^{15)}$ GSTs catalyze the binding of a large variety of (potentially toxic) electrophiles to the sulfhydryl group of glutathione (GSH), generally resulting in more water-soluble and less toxic molecules, which are subsequently excreted in bile or urine. The GSH/GST biotransformation system is involved in the detoxification of xenobiotics, carcinogens, free radicals and peroxides and therefore most likely involved in the protection against carcinogenesis. ${ }^{15)}$ Expression of GST classes $\alpha, \mu, \pi$ and $\theta$ in humans varies markedly among different tissues and also exhibits large inter-individual differences. GSH content also varies among different tissues and may decrease with age in both men and women. ${ }^{16}$ )

The aim of this study was to evaluate GSH content and GST enzyme activity, including GST isoenzymes $\alpha, \mu, \pi$ and $\theta$ in small intestinal mucosa of untreated coeliacs with active gluten-sensitive enteropathy, as compared to controls. Moreover, we investigated whether a correlation 
could be found between the GSH/GST system and the degree of mucosal abnormalities in gluten-sensitive enteropathy.

\section{PATIENTS AND METHODS}

Twelve untreated patients with coeliac disease (7 females, 5 males; mean age 49 years; range 28-64 years), in whom a flat jejunal mucosa was seen in small intestinal biopsies (Marsh IIIC) and 23 normal subjects (14 females, 9 males; mean age 36 years; range $18-69$ years) were studied in the first part of this study. In the second part of the study, 26 other coeliac patients were further investigated. All had been on a gluten-free diet for at least 1 year. Eleven of them were in remission ( 5 females, 6 males; mean age 42 years; range $28-63$ years), showing normalization of the jejunal mucosa (Marsh 0-I). In the other 15 coeliacs, small intestinal biopsies showed persisting pathological abnormalities in different gradations. Six patients (3 females, 3 males; mean age 62 years; range 52-69 years) had subtotal villous atrophy (Marsh IIIB), 5 patients (3 females, 2 males; mean age 55 years; range 40-79 years) had partial villous atrophy (Marsh IIIA) and 4 patients (all females; mean age 57 years; range 44-65 years) had infiltrative/crypt-hyperplastic lesions (Marsh II). We measured GSH content and GST enzyme activity, including isoenzymes $\alpha, \mu, \pi$ and $\theta$, in small intestinal biopsies of all subjects.

The small intestinal tissue samples were taken by an endoscopically guided Crosby capsule from the jejunal mucosa. Biopsies were immediately frozen in liquid nitrogen and stored at $-80^{\circ} \mathrm{C}$. For further analyses, the samples were homogenized, and $150000 \mathrm{~g}$ supernatants were prepared as described previously. ${ }^{9}$ Protein concentration was assayed in triplicate by the method of Lowry et al. using bovine serum albumin as a standard. ${ }^{17)} \mathrm{GSH}$ was quantified by high-performance liquid chromatography after reaction with monobromobimane. ${ }^{9)}$ GST activity was determined according to Habig et al. using 1-chloro-2,4dinitrobenzene as a substrate. ${ }^{18)}$ GST isoenzyme levels were measured after densitometric analyses of immunoblots. ${ }^{9)}$ In short, cytosolic fractions were subjected to sodium dodecyl sulfate polyacrylamide gel electrophoresis (11\% acrylamide, w/v), and subsequently to western blotting, using a semidry blotting system (Novablot II, Pharmacia, Uppsala, Sweden). Western blots were incubated with monoclonal antibodies against human GST class $\alpha$, $\mu, \pi$ and $\theta$. Class $\alpha$ antibodies react with human GST A11, GST A1-2 and GST A2-2.9) Class $\mu$ antibodies recognize human GST M1a-1a, GST M1a-1b and GST M1b1b. ${ }^{9)}$ Class $\pi$ antibodies react with human GST P1-1.9) Class $\theta$ antibodies react with GST T1-1.. ${ }^{19)}$ The specific binding of the monoclonal antibodies to the isoenzymes was detected by incubation with peroxidase-conjugated rabbit anti-mouse immunoglobulin (Dakopatts, Glostrup, Denmark) and subsequent development of the peroxidase label with 4-chloro-1-naphthol and hydrogen peroxide (for GST $\alpha, \mu$ and $\pi$ ). Staining of GST $\theta$ was performed in $0.1 \%$ 3,3'-diaminobenzidine (Sigma Chemical Co., St. Louis, MO) in phosphate-buffered saline (PBS) containing $0.01 \%$ hydrogen peroxide (Merck, Darmstadt, Germany), $0.34 \mathrm{~g} /$ liter imidazole and $0.26 \mathrm{~g} /$ liter cobalt chloride $6 \mathrm{H}_{2} \mathrm{O}$. Staining intensity on the immunoblots was quantified using a laser densitometer (Ultroscan XL, LKB, Bromma, Sweden). Known amounts of purified GSTs were run in parallel with the experimental samples and served as standards for the calculation of the isoenzyme levels in the cytosolic fractions. Detection limit of the western blot assay is approximately $40 \mathrm{ng} / \mathrm{mg}$ protein.

Small intestinal histology was analyzed according to a modified Marsh classification. ${ }^{20-23)}$ This classification comprises three distinct, consecutive phases of mucosal abnormalities. In Marsh I, the mucosal architecture is unchanged, but a marked infiltration of the villous epithelium by lymphocytes is seen (more than 30 lymphocytes per 100 enterocytes). In Marsh II, the intra-epithelial infil-

Table I. Glutathione and Glutathione S-Transferases in Small Intestine of Control Subjects and Coeliac Patients

\begin{tabular}{|c|c|c|c|c|c|c|}
\hline Tissue & GSH & GST & $\alpha$ & $\mu$ & $\pi$ & $\theta$ \\
\hline Control & $27.2 \pm 2.5$ & $464 \pm 39^{a, b)}$ & $6.47 \pm 0.48^{a, b)}$ & $0.91 \pm 0.25$ & $2.19 \pm 0.32$ & $0.54 \pm 0.07$ \\
\hline Remission $(n=11)$ & $22.5 \pm 1.3$ & $359 \pm 36^{a)}$ & $5.79 \pm 0.79^{a)}$ & $0.66 \pm 0.19$ & $1.96 \pm 0.25$ & $0.44 \pm 0.08$ \\
\hline Marsh II $\quad(n=4)$ & $32.0 \pm 4.6$ & $240 \pm 67^{a)}$ & $2.75 \pm 0.69^{a)}$ & $0.83 \pm 0.43$ & $2.15 \pm 0.55$ & $0.57 \pm 0.25$ \\
\hline Marsh IIIA $(n=5)$ & $17.0 \pm 5.0$ & $191 \pm 56^{a)}$ & $2.19 \pm 0.90^{a)}$ & $0.82 \pm 0.34$ & $1.54 \pm 0.31$ & $0.37 \pm 0.20$ \\
\hline Marsh IIIB $(n=6)$ & $17.0 \pm 1.7$ & $228 \pm 43^{a)}$ & $2.73 \pm 0.58^{a)}$ & $0.65 \pm 0.32$ & $2.08 \pm 0.34$ & $0.30 \pm 0.10$ \\
\hline Marsh IIIC $(n=12)$ & $21.7 \pm 2.4$ & $220 \pm 23^{a, b)}$ & $2.79 \pm 0.65^{a, b)}$ & $0.54 \pm 0.19$ & $2.15 \pm 0.46$ & $0.33 \pm 0.09$ \\
\hline
\end{tabular}

Data are given as mean \pm SEM.

a) Spearman's rank correlation coefficient: GST, -0.596 ; GST $\alpha,-0.620(P<0.001)$.

b) Two-tailed $t$ test, $P<0.001$.

GSH, total glutathione content in $\mathrm{nmol} / \mathrm{mg}$ protein; GST, GST enzyme activity in $\mathrm{nmol} / \mathrm{mg}$ protein $\cdot \mathrm{min} ; \mathrm{GST} \alpha, \mu, \pi, \theta$ content in $\mu \mathrm{g} / \mathrm{mg}$ protein. 
tration by lymphocytes is accompanied by crypt hyperplasia: enlargement and budding of crypts in which there is an increased mitotic rate. Marsh III comprises of intra-epithelial infiltration by lymphocytes, crypt hyperplasia and villous atrophy. In Marsh IIIA partial villous atrophy, villi are blunted and shortened; in Marsh IIIB, sub-total villous atrophy, villi are clearly atrophic but still recognizable, and in Marsh IIIC, total villous atrophy, the villi are absent or rudimentary, the mucosa resembling colonic mucosa.

Statistical analysis was performed, using a two-tailed $t$ test for unequal variances for comparison of GSH content, total GST enzyme activities, and GST isoenzymes in coeliacs with a flat mucosa (Marsh IIIC) and control subjects. The Spearman's $\rho$ rank correlation coefficient was calculated for GSH, total GST and GST isoenzymes for all subjects, divided into groups of consecutive, intermediate mucosal abnormalities: normal subjects, coeliacs in remission (Marsh 0-I), Marsh II, Marsh IIIA, Marsh IIIB and Marsh IIIC.

The study was approved by the local ethical committee on human experimentation.

\section{RESULTS}

Results of analyses of the levels of GSH, total GST enzyme activity and GST $\alpha, \mu, \pi$ and $\theta$ levels in jejunal mucosa of untreated coeliac patients (Marsh IIIC) and normal subjects are given in Table I. Total GST and GST $\alpha$ are markedly lower in untreated coeliacs compared with controls (total GST, $220 \pm 79$ vs. $464 \pm 189 \mathrm{nmol} / \mathrm{mg}$ protein $\cdot \min \quad( \pm \mathrm{SD}) \quad(P<0.001) ; \mathrm{GST} \alpha, 2.79 \pm 2.46$ vs. $6.47 \pm 2.29 \mu \mathrm{g} / \mathrm{mg}$ protein $(P<0.001))$. Content of $\mathrm{GSH}$ and levels of GST $\mu, \pi$ and $\theta$ are not significantly different in small intestinal tissue of untreated coeliacs compared with controls.

In Marsh IIIB, Marsh IIIA and Marsh II, GST enzyme activity and levels of GST $\alpha$ are also lowered and levels return to normal values in coeliacs in remission (Table I). The suppression of both variables is proportionate to the degree of mucosal abnormalities. This inverse relationship is expressed in the Spearman's $\rho$ correlation coefficient, which is -0.596 for the total GST variable $(P<0.001)$ and -0.620 for GST $\alpha$ (Fig. 1). Again, GSH and GST $\mu, \pi$ and $\theta$ are not significantly different between patients and controls.

\section{DISCUSSION}

We have demonstrated that total GST enzyme activity in the small intestinal mucosa of patients with untreated Marsh IIIC coeliac disease is significantly lower than in the small intestinal mucosa of healthy subjects. This low GST enzyme activity is solely due to significantly lower GST $\alpha$ levels. In addition, GST enzyme activity and levels
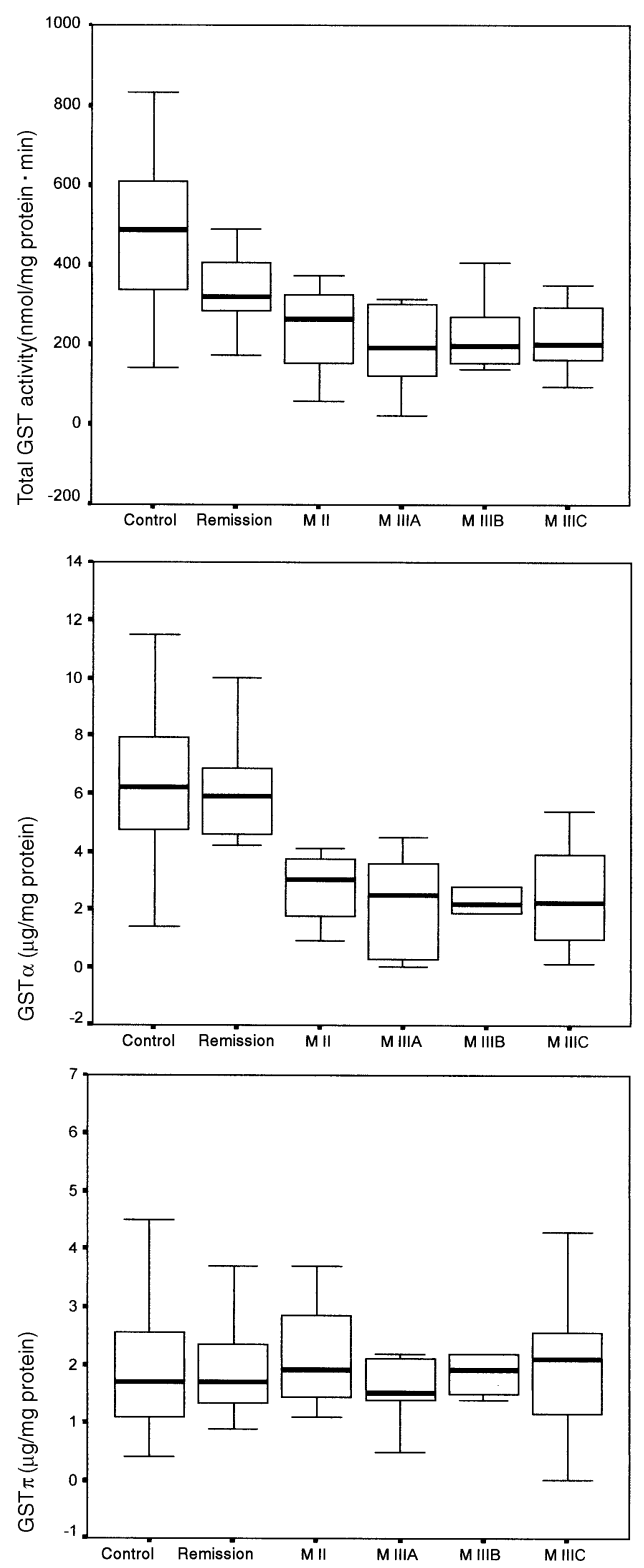

Fig. 1. Total GST activity, GST $\alpha$ content and GST $\pi$ content in small intestinal biopsies of controls and coeliac patients with increasing degree of mucosal pathology (Marsh 0-IIIC). Spearman's $\rho$ correlation coefficient for total GST, -0.596 ; GST $\alpha$, $-0.620(P<0.001)$.

of GST $\alpha$ appear to be closely related to the degree of mucosal damage in coeliacs. Mucosal protein levels of GST $\mu, \pi$ and $\theta$ and GSH content were not significantly lower in coeliacs as compared to control subjects.

The distribution of GST isoenzymes is tissue-specific. GST $\alpha$ is dominantly expressed in the liver, kidney and small intestine. GST $\pi$ is present as a major form in organs, such as the lungs, breasts, large intestine and urine blad- 
der. GST $\mu$ is expressed at relatively low levels in many organs, whereas little is known about the distribution of GST $\theta$ isoforms.

Focusing on the small intestine, it has been demonstrated, that GST $\alpha$ is dominantly expressed in the apex of the villi. Given this distribution of GST isoenzymes, the low GST $\alpha$ levels in coeliacs with a flat mucosa, i.e. without villi, and the gradual increase in GST $\alpha$ levels with reappearing villi, is in accordance with what may be expected.

Substantial evidence has accumulated to suggest that high levels of GSTs protect against cancer. In humans, polymorphisms in GSTs are present, resulting in a significant reduction or even complete absence of enzyme activity. About $40 \%$ of all Caucasians lack GST M1, ${ }^{24-26)}$ whereas GST T1 is absent in about $20 \%$ of the Caucasian population. ${ }^{27)}$ Complete absence or reduced levels of GST M1, GST TI or GST enzyme activity have been implicated in increased risk for malignancies in pituitary, ${ }^{28)}$ larynx ${ }^{29)}$ bladder ${ }^{29,30)}$ stomach, ${ }^{31)}$ colon $^{31-34)}$ and possibly lung. ${ }^{24,25,35)}$ Increased cytogenetic damage was observed in in vitro studies with GST M1-deficient human blood cells, ${ }^{36,37)}$ and higher levels of polycyclic aromatic hydrocarbon DNA adducts were found in lung tissue of GST M1-deficient subjects. ${ }^{38)}$ Human tissues at high risk for malignant degeneration such as Barrett's esophagus ${ }^{9}, 39$ ) contain significantly lower levels of GST as compared to normal esophageal tissue. Human (gastrointestinal) tissues with a low tumor incidence (liver, small intestine) contain high GST enzyme levels, whereas tissues with a high tumor risk (colon, lung, breast) have relatively low levels of GST. ${ }^{9,15)}$ In addition, the tissues mentioned above

\section{REFERENCES}

1) Harris, O. D., Cooke, W. T., Thompson, H. and Waterhouse, J. A. H. Malignancy in adult coeliac disease and idiopathic steatorrhoea. Am. J. Med., 42, 899-912 (1967).

2) Holmes, G. K. T., Stokes, P. L., Sorahan, T. M., Prior, P., Waterhouse, J. A. H. and Cooke, W. T. Coeliac disease, gluten free diet and malignancy. Gut, 17, 612-619 (1976).

3) O'Driscoll, B. R. C., Stevens, F. M., O'Gorman, T. A., Finnegan, P., McWeeney, J. J., Little, M. P., Connolly, C. E. and McCarthy, C. F. HLA type of patients with coeliac disease and malignancy in the West of Ireland. Gut, 23, 662-665 (1982).

4) Brandt, L., Hagander, B., Norden, A. and Stenstam, M. Lymphoma of the small intestine in adult coeliac disease. Acta Med. Scand., 204, 467-470 (1978).

5) Seihy, W. S. and Gallagher, N. D. Malignancy in a 19 year experience of adult coeliac disease. Dig. Dis. Sci., 24, 684688 (1979).

6) Logan, R. F. A., Rifkind, E. A., Turner, I. D. and Ferguson, with low tumor incidence have a high GST $\alpha$ content, whereas those with a high tumor incidence generally have low GST $\alpha$ content, suggesting that especially GST $\alpha$ is protective. ${ }^{9,15}$ Inhibition of chemically induced esophageal, gastric or colorectal tumors in rodents was shown by adding naturally occurring compounds from vegetables and fruits such as ellagic acid, organic sulfides or isothiocyanates to their diets. ${ }^{15)}$ These compounds are able to raise the levels of GSTs in several organs, including those of the gastrointestinal tract. ${ }^{40-44)}$ Nonsteroidal anti-inflammatory drugs, which have been shown to reduce the risk for colorectal adenomas and carcinomas, ${ }^{45,46)}$ are also able to enhance GSTs of the rat gastrointestinal tract. ${ }^{47,48)}$ Such compounds might also be effective in reducing the cancer risk in patients with coeliac disease.

We conclude that depression of the GSH/GST biotransformation system, predominantly class $\alpha$ GSTs, may explain in part the carcinogenic risk in active coeliac disease. Theoretically, the correlation between consecutive reappearance of villi in coeliacs on a gluten-free diet and a gradual increase of total GST enzyme activity and GST $\alpha$ levels, implies that when recovery of mucosal pathology is slow, or incomplete while on a gluten-free diet, these subjects are still at risk for developing malignancies. This emphasizes the need for advising patients to adhere strictly to their gluten-free diet and suggests the advisability of follow-up small intestinal biopsies in coeliacs on a glutenfree diet, to identify patients who have incomplete histological recovery.

(Received October 23, 2000/Revised December 18, 2000/ Accepted December 25, 2000)

A. Mortality in coeliac disease. Gastroenterology, 97, 265-271 (1989).

7) Holmes, G. K. T., Prior, P., Lane, M. R., Pope, R. N. and Allan, R. N. Malignancy in coeliac disease: effect of a gluten free diet. Gut, 30, 333-338 (1989).

8) Mannervik, B. and Danielson, U. H. Glutathione transferases: structure and catalytic activity. CRC Crit. Rev. Biochem., 23, 283-337 (1988).

9) Peters, W. H. M., Roelofs, H. J. M., Hectors, M. P. G., Nagengast, F. M. and Jansen, J. B. M. J. Glutathione and glutathione S-transferases in Barrett's epithelium. Br. J. Cancer, 67, 1413-1417 (1993).

10) Peters, W. H. M., Wormskamp, N. G. M. and Thies, E. Expression of glutathione S-transferases in normal gastric mucosa and in gastric tumours. Carcinogenesis, 11, 15931596 (1990).

11) Hayes, P. C., Harrison, D. J., Bouchier, L. A. D., McLellan, L. I. and Hayes, J. D. Cytosolic and microsomal glutathione S-transferase isoenzymes in normal human liver 
and intestinal epithelium. Gut, 30, 854-859 (1989).

12) Peters, W. H. M., Nagengast, F. M. and Wobbes, T. Glutathione S-transferases in normal and cancerous colon tissue. Carcinogenesis, 10, 2371-2374 (1989).

13) Peters, W. H. M., Kock, L., Nagengast, F. M. and Kremers, P. G. Biotransformation enzymes in human intestine: critical low levels in the colon? Gut, 32, 408-412 (1991).

14) Moorghen, M., Cairns, J., Forrester, L. M., Hayes, J. D., Hall, A., Cattan, A. R., Wolf, C. R. and Harris, A. L. Enhanced expression of glutathione S-transferases in colorectal carcinoma compared to non-neoplastic mucosa. Carcinogenesis, 12, 13-17 (1991).

15) Hayes, J. D. and Pulford, D. J. The glutathione 5-transferase supergene family: regulation of GST and the contribution of the isoenzymes to cancer chemoprotection and drug resistance. Crit. Rev. Biochem. Mol. Biol., 30, 445600 (1995).

16) Van Lieshout, E. M. M. and Peters, W. H. M. Age and gender dependent levels of glutathione and glutathione Stransferases in human lymphocytes. Carcinogenesis, 19, 1873-1875 (1998).

17) Lowry, O. H., Rosebrough, N. J., Farr, A. L. and Randall, R. J. Protein measurement with the Folin phenol reagent. J. Biol. Chem., 193, 265-275 (1951).

18) Habig, W. H., Pabst, M. J. and Jacoby, W. B. Glutathione S-transferases. The first enzymatic step in mercapturic acid formation. J. Biol. Chem., 249, 7130-7139 (1974).

19) Juronen, E., Tasa, G., Uusküla, M., Pooga, M. and Mikselaar, A. V. Production and characterization of monoclonal antibodies against class theta glutathione S-transferase T1-1. Hybridoma, 15, 77-82 (1996).

20) Marsh, M. N. Gluten, major histocompatibility complex and the small intestine: a molecular and immunobiologic approach to the spectrum of gluten sensitivity ("celiac sprue'). Gastroenterology, 102, 330-354 (1992).

21) Marsh, M. N. and Crowe, P. T. Morphology of the mucosal lesion in gluten sensitivity. Baillieres Clin. Gastroenterol., 9, 273-293 (1995).

22) Rostami, K., Kerckhaert, J., Blomberg, B. M. E., Meijer, J. W. R. and Mulder, C. J. J. Sensitivity of antiendomysium and antigliadin antibodies in untreated celiac disease: disappointing in clinical practice. Am. J. Gastroenterol., 94, 888-894 (1999).

23) Wahab, P. J., Crusius, J. B. A., Meijer, J. W. R., Uil, J. J. and Mulder, C. J. J. Cyclosporin in the treatment of adults with refractory coeliac disease - an open pilot study. Aliment. Pharmacol. Ther., 14, 767-774 (2000).

24) Seidegård, J., Pero, R. W., Markowik, M. M., Roush, G., Miller, D. G. and Beattie, E. J. Isoenzymes of glutathione S-transferase (class mu) as a marker for susceptibility to lung cancer; a follow up study. Carcinogenesis, 11, 33-36 (1990).

25) Brockmoller, J., Kerb, R., Drakoulis, N., Nitz, M. and Roots, I. Genotype and phenotype of glutathione S-transferase class $\mu$ isoenzymes mu and psi in lung cancer patients and controls. Cancer Res., 53, 1004-1011 (1993).
26) Zhong, S., Howie, A. F., Ketterer, B., Taylor, J., Hayes, J. D., Beckett, G. J., Wathen, C. G., Wolf, C. R. and Spurr, N. $\mathrm{K}$. Glutathione S-transferase mu locus: use of genotype and phenotype assays to assess association with lung cancer susceptibility. Carcinogenesis, 12, 1533-1537 (1991).

27) Nelson, H. H., Wiencke, J. K., Christiani, D. C., Cheng, T. J., Zuo, Z. F., Schwartz, B. S., Lee, B. K., Spitz, M. R., Wang, M., Xu, X. and Kelsey, K. T. Ethnic differences in the prevalence of the homozygous deleted genotype of glutathione S-transferase theta. Carcinogenesis, 16, $1243-$ 1245 (1995).

28) Feyer, A. A., Zliao, L., Alldersea, J., Boggild, M. D., Perrett, W., Clayton, R. N., Jones, P. W. and Strange, R. C. The glutathione S-transferases: polymerase chain reaction studies on the frequency of the GSTM10 genotype in patients with pituitary adenomas. Carcinogenesis, 14, 563566 (1993).

29) Lafuente, A., Pujol, F., Carretero, P., Villa, I. P. and Cuchi, A. Human glutathione S-transferase $\mu$ (GST $\mu$ ) deficiency as a marker for the susceptibility to bladder and larynx cancer among smokers. Cancer Lett., 68, 49-54 (1993).

30) Bell, D. A., Taylor, J. A., Paulson, D. F., Robertson, C. N., Mohler, J. L. and Lucier, G. W. Genetic risk and carcinogen exposure: a common inherited defect of the carcinogenmetabolism gene glutathione S-transferase Ml (GSTM 1) that increases susceptibility to bladder cancer. J. Natl. Cancer Inst., 85, 1159-1164 (1993).

31) Strange, R. C., Matharoo, B., Faulder, G. C., Jones, P., Cotton, W., Elder, J. I. B. and Deakin, M. The human glutathione S-transferases: a case control study of the incidence of the GST 10 phenotype in patients with adenocarcinoma. Carcinogenesis, 12, 25-28 (1991).

32) Chenevix-Trench, G., Young, J., Coggan, M. and Board, P. Glutathione S-transferase Ml and Ti polymorphism: susceptibility to colon cancer and age of onset. Carcinogenesis, 16, 1655-1657 (1995).

33) Tobi, M., Darmon, F., Rozen, P., Avigdor, S., Rattan, J., Santo, M. and Barnea, E. R. Large-bowel mucosal biotransformation activity in persons at high risk for colorectal cancer. Scand. J. Gastroenterol., 28, 958-962 (1993).

34) Szarka, C. E., Pfeiffer, G. R., Hum, S. T., Everly, L. C., Balshem, A. M., Moore, D. F., Litwin, S., Goosenberg, E. B., Frucht, H., Engstrom, P. F. and Clapper, M. L. Glutathione S-transferase activity and glutathione S-transferase $\mu$ expression in subjects with risk for colorectal cancer. Cancer Res., 55, 2789-2793 (1995).

35) Hirvonen, A., Husgafvel-Pursiainen, K., Anttila, S. and Vainio, H. The GSTM1 null phenotype as a potential risk modifier for squamous cell carcinoma of the lung. Carcinogenesis, 14, 1479-1481 (1993).

36) Wiencke, J. K., Kelsey, K. T., Lamela, R. A. and Toscano, W. A. Human glutathione S-transferase deficiency as a marker of susceptibility to epoxide induced cytogenetic damage. Cancer Res., 50, 1585-1590 (1990).

37) Van Poppel, G., de Vogel, N., van Bladeren, P. J. and Kok, 
F. J. Increased cytogenetic damage in smokers deficient in glutathione S-transferase isoenzyme mu. Carcinogenesis, 13, 303-305 (1992).

38) Shields, P. G., Bowman, E. D., Harrington, A. M., Doan, V. T. and Weston, A. Polycyclic aromatic hydrocarbon-DNA adducts in human lung and cancer susceptibility genes. Cancer Res., 53, 3486-3492 (1993).

39) Van Lieshout, E. M. M., Tiemessen, D. M., Witteman, B. J. M., Jansen, J. B. M. J. and Peters, W. H. M. Low glutathione and glutathione S-transferase levels in Barrett's esophagus as compared to normal esophageal epithelium. Jpn. J. Cancer Res., 90, 81-85 (1999).

40) Sparnins, V. L., Chuan, J. and Wattenberg, L. W. Enhancement of glutathione S-transferase activity of the esophagus by phenols, lactones and benzyl isothiocyanate. Cancer Res., 42, 1205-1207 (1982).

41) Sparnins, V. L., Barany, G. and Wattenberg, L. W. Effects of organosulfur compounds from garlic and onions on benzo(a)pyrene-induced neoplasia and glutathione S-transferase activity in the mouse. Carcinogenesis, 9, 131-134 (1988).

42) Das, M., Bickers, D. R. and Mukhtar, H. Effect of ellagic acid on hepatic and pulmonary xenobiotic metabolism in mice: studies on the mechanism of its anticarcinogenic action. Carcinogenesis, 6, 1409-1413 (1985).
43) Maurya, A. K. and Singh, S. V. Differential induction of glutathione transferase isoenzymes of mice stomach by diallyl sulfide, a naturally occurring anticarcinogen. Cancer Lett., 57, 121-129 (1991).

44) Rhan, S. G., Katiyar, S. K., Agarwal, R. and Mukhtar, H. Enhancement of antioxidant and phase II enzymes by oral feeding of green tea polyphenols in drinking water to SKH1 hairless mice: possible role in cancer chemoprevention. Cancer Res., 52, 4050-4052 (1992).

45) Giardiello, F. M., Hamilton, S. R., Krush, A. J., Piantadosi, S., Hylind, L. M., Celano, P., Booker, S. V., Robinson, C. R. and Offerhaus, G. J. A. Treatment of colonic and rectal adenomas with sulindac in familial adenomatous polyposis. N. Engl. J. Med., 328, 1313-1316 (1993).

46) Thun, M. J., Nomboodiri, M. M. and Heath, V. W., Jr. Aspirin use and the reduced risk of fetal colon cancer. $N$. Engl. J. Med., 325, 1593-1596 (1991).

47) Van Lieshout, E. M. M., Tiemesen, D. M., Peters, W. H. M. and Jansen, J. B. M. J. Effects of nonsteroidal antiinflammatory drugs on glutathione S-transferases of the rat digestive tract. Carcinogenesis, 18, 485-490 (1997).

48) Van Lieshout, E. M. M., Tiemessen, D. M., Roelofs, H. M. J. and Peters, W. H. M. Nonsteroidal antiinflammatory drugs enhance glutathione S-transferase theta levels in rat colon. Biochim. Biophys. Acta, 1381, 305-311 (1998). 